\title{
Solvents Applied in the Field of Cellulose Chemistry - A Mini Review
}

\author{
Thomas Heinze, Andreas Koschella \\ Friedrich Schiller University of Jena, Germany
}

\begin{abstract}
Important cellulose solvents are described based on the systematization of derivatizing and non-derivatizing solvents. Advances and limitations of the homogeneous phase chemistry of the biopolymer will be discussed based on new results considering adequately own research work in the field.
\end{abstract}

Keywords: Biopolymers, cellulose solvents, esterification, functionalization of polymers, shaping.

\section{Introduction}

The efficient dissolution of cellulose is a long-standing goal in cellulose research and development. Dissolved cellulose is an indispensable prerequisite for

- Characterization (e.g., molecular weight and molecular weight distribution)

- Shaping (e.g., fibre spinning of pulp) and

- Homogeneous phase chemistry

of the polymer and of great commercial importance. From the commercial point of view, the viscose process, i.e., the cellulose xanthogenate, which is prepared by treating cellulose with $\mathrm{CS}_{2}$ and $\mathrm{NaOH}$, is by far the most important route to cellulose solutions. The viscose process, invented by Cross and co-workers in 1892, is practiced today with an output of about 3 million tons annually worldwide ${ }^{[1]}$.

In addition, aqueous solutions of metal complexes like cuproethylene diamine or cuprammonium hydroxide (Cuam) are cellulose solvents known for a rather long time $^{[2]}$. The Cuam process uses the solubility of cellulose in cupric hydroxide or a mixture of a basic copper salt and concentrated ammonia. Spinning into water regenerates the cellulose and in addition, an acidic bath for regeneration is applied. The Cuam process still keeps its importance for production of filaments, staple fibres, and membranes, despite the fact that a significant reduction in production capacity took place during the last few years ${ }^{[3-5]}$. Moreover, solvents of this type are applied for the determination of the molecular weight of cellulose by viscometry.

\section{Systematization of cellulose solvents}

Several proposals have been made in recent years to systemize the cellulose solvents known today. In this paper the classification according to the two categories of nonderivatizing and derivatizing solvents is considered to be most appropriate (Figure 1). The term "non-derivatizing" denotes systems dissolving the polymer by intermolecular interactions only. Aqueous transition metal complex solvents are conventionally included in this category despite an often very strong interaction, as no covalent interactions occur. The group of "derivatizing" solvents comprises all the systems where dissolution occurs in combination with formation of "unstable" ether, ester, or acetal derivatives. A specification within the large group of solvents acting via the formation of covalent derivatization of the polymer is given by the criterion that the derivative formed in a socalled derivatizing solvent is easily decomposed to regenerate cellulose by changing the medium (e.g., nonaqueous to aqueous) or the $\mathrm{pH}$-value of the medium. Both categories of solvents comprises aqueous and non-aqueous media.

Before presenting new results in the field of cellulose solvents, a systematic description of important cellulose solvents shall be given following the classification mentioned above. In particular the homogeneous phase chemistry of cellulose will be discussed presenting adequately own research results. As mentioned above, a suitable, though approximate classification of cellulose solvents which will be used in this paper is given in Figure 1 and identifies three types of systems, namely non-

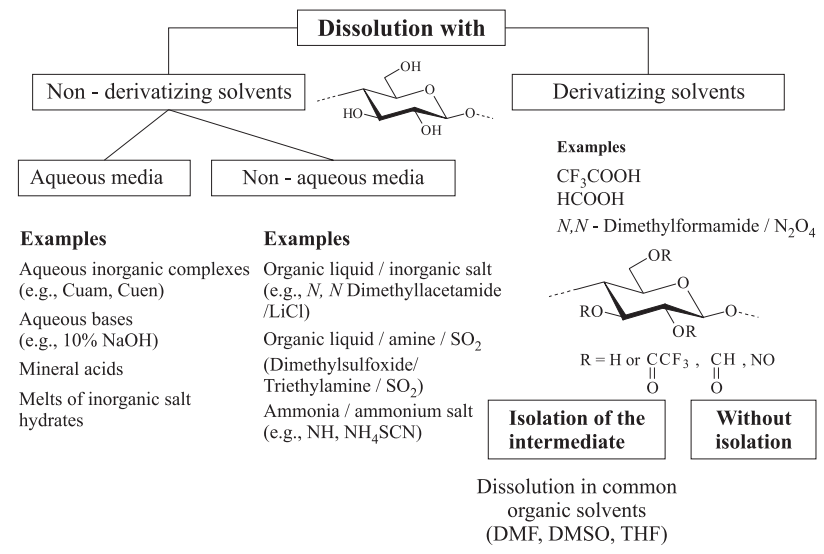

Figure 1. Classification of cellulose solvents. 
Table 1. Examples of aqueous cellulose solvents.

\begin{tabular}{|c|c|c|}
\hline Type of compound & Solvent Abbreviation & Active species \\
\hline \multirow[t]{11}{*}{$\begin{array}{l}\text { Transition metal complexes with amines } \\
\text { or } \mathrm{NH}_{3}\end{array}$} & Cadoxen & {$\left[\mathrm{Cd}\left(\mathrm{H}_{2} \mathrm{~N}-\left(\mathrm{CH}_{2}\right)_{2}-\mathrm{NH}_{2}\right)_{3}\right](\mathrm{OH})_{2}$} \\
\hline & Cdtren & {$\left[\mathrm{Cd}\left(\mathrm{NH}_{2} \mathrm{CH}_{2} \mathrm{CH}_{2}\right)_{3} \mathrm{~N}\right](\mathrm{OH})_{2}$} \\
\hline & Cooxen & {$\left[\mathrm{Co}\left(\mathrm{H}_{2} \mathrm{~N}-\left(\mathrm{CH}_{2}\right)_{2}-\mathrm{NH}_{2}\right)_{2}\right](\mathrm{OH})_{2}$} \\
\hline & Cupren & {$\left[\mathrm{Cu}\left(\mathrm{H}_{2} \mathrm{~N}-\left(\mathrm{CH}_{2}\right)_{3}-\mathrm{NH}_{2}\right)_{2}\right](\mathrm{OH})_{2}$} \\
\hline & Cuam & {$\left[\mathrm{Cu}\left(\mathrm{NH}_{3}\right)_{4}\right](\mathrm{OH})_{2}$} \\
\hline & Cuen & {$\left[\mathrm{Cu}\left(\mathrm{H}_{2} \mathrm{~N}-\left(\mathrm{CH}_{2}\right)_{2}-\mathrm{NH}_{2}\right)_{2}\right](\mathrm{OH})_{2}$} \\
\hline & Nioxam & {$\left[\mathrm{Ni}\left(\mathrm{NH}_{3}\right)_{6}\right](\mathrm{OH})_{2}$} \\
\hline & Nioxen & {$\left[\mathrm{Ni}\left(\mathrm{H}_{2} \mathrm{~N}-\left(\mathrm{CH}_{2}\right)_{2}-\mathrm{NH}_{2}\right)_{3}\right](\mathrm{OH})_{2}$} \\
\hline & Nitren & {$\left[\mathrm{Ni}\left(\mathrm{NH}_{2} \mathrm{CH}_{2} \mathrm{CH}_{2}\right)_{3} \mathrm{~N}\right](\mathrm{OH})_{2}$} \\
\hline & Pden & {$\left[\mathrm{Pd}\left(\mathrm{H}_{2} \mathrm{~N}-\left(\mathrm{CH}_{2}\right)_{2}-\mathrm{NH}_{2}\right](\mathrm{OH})_{2}\right.$} \\
\hline & Zincoxen & {$\left[\mathrm{Zn}\left(\mathrm{H}_{2} \mathrm{~N}-\left(\mathrm{CH}_{2}\right)_{2}-\mathrm{NH}_{2}\right)_{2}\right](\mathrm{OH})_{2}$} \\
\hline Transition metal complexes with tartaric acid & $\mathrm{FeTNa}$ & $\mathrm{Na}_{6}\left[\mathrm{Fe}\left(\mathrm{C}_{4} \mathrm{H}_{3} \mathrm{O}_{6}\right)_{3}\right]$ \\
\hline \multirow[t]{4}{*}{ Ammonium hydroxides } & Triton B & Trimethylbenzyl ammonium hydroxide \\
\hline & TEOH & Tetraethylammonium hydroxide \\
\hline & Triton F & Dimethyldibenzyl ammonium hydroxide \\
\hline & $\mathrm{GuOH}$ & Guanidinium hydroxide \\
\hline Alkali hydroxides a) & & $\begin{array}{l}\mathrm{NaOH} \\
\mathrm{LiOH}\end{array}$ \\
\hline
\end{tabular}

a) Cellulose with limited degree of polymerization only.

derivatizing and derivatizing ones subdividing in aqueous and non-aqueous systems.

\section{Aqueous non-derivatizing solvents}

Aqueous solvents for cellulose, e.g., solutions of inorganic salts and complex compounds, were widely used for cellulose regeneration. The best known solvents of this group are cuprammonium hydroxide (Cuam) and cupriethylenediamine hydroxide (Cuen). Regeneration of membranes from Cuam solution provides high quality products for hemodialysis ${ }^{[6]}$. It is even possible to dissolve the polymer in about $10 \%$ aqueous $\mathrm{NaOH}$ solution, however, the solubility is limited to cellulose of comparably low degree of polymerization (DP) of up to 200. Recent results were published ${ }^{[7]}$. Typical aqueous solvents are summarized in Table 1.

\section{Chemical modification of cellulose dissolved in aqueous solvents}

A number of modern aqueous solvents, e.g., the aqueous solution of $\mathrm{Ni}(\operatorname{tren})(\mathrm{OH})_{2}$ [tren=tris(2-aminoethyl)amine], were studied in terms of the mechanism of dissolution and for their potential as medium for homogeneous etherification reactions ${ }^{[8,9]}$.

It is possible to convert cellulose dissolved in Ni-tren [concentrations of up to $10 \%(\mathrm{w} / \mathrm{v})$ ] in a fully homogeneous process to carboxymethyl cellulose $(\mathrm{CMC})^{[10]}$. Structure investigations by means of ${ }^{1} \mathrm{H}-\mathrm{NMR}$ analysis after chain degradation and HPLC analysis after complete depolymerization revealed that these products show a statistic content of the different repeating units and a distribution of the carboxymethyl functions on the level of the anhydroglucose unit (AGU) in the order $C-2 \geq C-6>C$-3, i.e., they posses the same functionalization pattern as ethers prepared in a highly swollen state as applied for commercial production of CMC. This result clearly shows that both simple activation of cellulose with aqueous $\mathrm{NaOH}$ and the complete dissolution of the polysaccharide lead to reactive sites with an almost even accessibility and hence there is no particular advantage of a conversion of the dissolved polymer ${ }^{[11]}$.

Besides aqueous solvent complexes, molten inorganic salt hydrates have gained attention as new solvents and media for cellulose modification. Thus, molten compounds of the 
Table 2. Examples of molten salt hydrates as swelling media and solvents for cellulose.

\begin{tabular}{|c|c|c|}
\hline Type & $\begin{array}{l}\text { Swelling } \\
\text { of cellulose }\end{array}$ & $\begin{array}{l}\text { Dissolution } \\
\text { of cellulose }\end{array}$ \\
\hline \multirow[t]{6}{*}{ Pure salt } & $\mathrm{LiCl}^{*} \mathrm{x} \mathrm{H}_{2} \mathrm{O}(2 \leq \mathrm{x} \leq 5)$ & $\mathrm{ZnCl}_{2} * 4 \mathrm{H}_{2} \mathrm{O}$ \\
\hline & $\mathrm{Zn}\left(\mathrm{NO}_{3}\right)_{2} * 6 \mathrm{H}_{2} \mathrm{O}$ & $\mathrm{LiClO}_{4} * 3 \mathrm{H}_{2} \mathrm{O}$ \\
\hline & $\mathrm{NaClO}_{4}{ }^{*} \mathrm{H}_{2} \mathrm{O}$ & $\mathrm{Zn}\left(\mathrm{NO}_{3}\right)_{2}{ }^{*} \mathrm{xH}_{2} \mathrm{O}(\mathrm{x}<6)$ \\
\hline & $\mathrm{Mg}\left(\mathrm{ClO}_{4}\right)_{2} * \mathrm{H}_{2} \mathrm{O}$ & $\mathrm{FeCl}_{3} * 6 \mathrm{H}_{2} \mathrm{O}$ \\
\hline & & $\mathrm{LiSCN} * 2 \mathrm{H}_{2} \mathrm{O}$ \\
\hline & & $\mathrm{LiI} * 2 \mathrm{H}_{2} \mathrm{O}$ \\
\hline \multirow[t]{6}{*}{ Salt mixture } & $2 \mathrm{iClO}_{4} * 3 \mathrm{H}_{2} \mathrm{O} / \mathrm{CaCl}_{2} * 6 \mathrm{H}_{2} \mathrm{O}$ & $\mathrm{LiClO}_{4} * 3 \mathrm{H}_{2} \mathrm{O} / \mathrm{MgCl}_{2} * 6 \mathrm{H}_{2} \mathrm{O}$ \\
\hline & & $\mathrm{LiClO}_{4} * 3 \mathrm{H}_{2} \mathrm{O} / \mathrm{Mg}\left(\mathrm{ClO}_{4}\right)_{2} / \mathrm{H}_{2} \mathrm{O}$ \\
\hline & & $\mathrm{LiCOl}_{4} * 3 \mathrm{H}_{2} \mathrm{O} / \mathrm{NaClO}_{4} / \mathrm{H}_{2} \mathrm{O}$ \\
\hline & & $\mathrm{LiCV} / \mathrm{ZnCl}_{2} / \mathrm{H}_{2} \mathrm{O}$ \\
\hline & & $\mathrm{NaSCN} / \mathrm{KSCN} / \mathrm{LiSCN} / \mathrm{H}_{2} \mathrm{O}$ \\
\hline & & $\mathrm{NaSCN} / \mathrm{KSCN} / \mathrm{Ca}(\mathrm{SCN})_{2} / \mathrm{H}_{2} \mathrm{O}$ \\
\hline
\end{tabular}

general formula $\mathrm{LiX}^{*} \mathrm{H}_{2} \mathrm{O}\left(\mathrm{X}^{-}=\mathrm{I}^{-}, \mathrm{NO}_{3}^{-}, \mathrm{CH}_{3} \mathrm{COO}^{-}, \mathrm{ClO}_{4}^{-}\right)$ were found to dissolve cellulose with DP values as high as 1500 (Table 2) ${ }^{[12,13]}$. Very effective is $\mathrm{LiClO}_{4} * 3 \mathrm{H}_{2} \mathrm{O}$ yielding transparent cellulose solutions within a few minutes. Furthermore, mixtures of $\mathrm{LiClO}_{4} * 3 \mathrm{H}_{2} \mathrm{O}$ with $\mathrm{Mg}\left(\mathrm{ClO}_{4}\right)_{2} * \mathrm{H}_{2} \mathrm{O}$ or the eutectic mixture of $\mathrm{NaSCN} / \mathrm{KSCN} / \mathrm{H}_{2} \mathrm{O}$ with different amounts of $\mathrm{LiSCN} * 2 \mathrm{H}_{2} \mathrm{O}$ were proved to dissolve cellulose. In case of $\mathrm{LiI} * 2 \mathrm{H}_{2} \mathrm{O}$ the dissolution is explained on the basis of the salt composition consisting of a soft polarizing anion and a small polarizing cation. In this regard it was surprising that $\mathrm{LiClO}_{4} * 3 \mathrm{H}_{2} \mathrm{O}$ gave the best results. The reason should be the strong interaction of cellulose with the hydrated $\mathrm{Li}^{+}$-ions and the structure of the molten $\mathrm{LiClO}_{4} * 3 \mathrm{H}_{2} \mathrm{O}$ as revealed by $\mathrm{X}$-ray scattering. The formation of an additional compound as stated for the interaction between cellulose and perchloric acid was excluded. Furthermore, it is possible to acquire NMR-spectra in these systems and to regenerate cellulose II from them.

Acetylation experiments were performed in $\mathrm{LiClO}_{4} * 3 \mathrm{H}_{2} \mathrm{O}$ at $110{ }^{\circ} \mathrm{C}$ and in $\mathrm{NaSCN} / \mathrm{KSCN} / \mathrm{LiSCN} * 2 \mathrm{H}_{2} \mathrm{O}$ at $130^{\circ} \mathrm{C}^{[14]}$. Among the acetylating reagents were acetic anhydride, ethyleneglycol diacetate, and vinyl acetate.

The best results were obtained with the mixture $\mathrm{NaSCN} /$ $\mathrm{KSCN} / \mathrm{LiSCN} * 2 \mathrm{H}_{2} \mathrm{O}$ and acetic anhydride using a remarkable excess of the acetylating reagent in the range of 50 to 100 -fold as summarized in Table 3. Degree of substitution (DS) values up to 2.4 were accessible during rather short reaction times (up to 3 hours). ${ }^{1} \mathrm{H}-\mathrm{NMR}$ spectra of propionylated samples revealed a preferred functionalization of the primary $\mathrm{OH}$ groups. X-ray experiments show broad signals proving an extended disordered structure. This structural feature should impart a high reactivity towards solid-solid reactions, e.g., blending with other polymers. Furthermore, the cellulose acetate synthesized in molten salt
Table 3. Experimental data and analytical results for the acetylation of cellulose in $\mathrm{NaSCN} / \mathrm{KSCN} / \mathrm{LiSCN} * 2 \mathrm{H}_{2} \mathrm{O}$ with acetic anhydride.

\begin{tabular}{ccccc}
\hline \multicolumn{2}{c}{ Reaction conditions } & \multicolumn{4}{c}{$\begin{array}{c}\text { Partial degree of } \\
\text { substitution }{ }^{\text {a) }} \text { at }\end{array}$} \\
\hline $\begin{array}{c}\text { Mole anhydride/ } \\
\text { anhydroglucose unit }\end{array}$ & $\begin{array}{c}\text { Time } \\
{[\mathrm{min}]}\end{array}$ & $O-6$ & $O-2$ and 3 & $\Sigma$ \\
\hline 100 & 180 & 0.91 & 1.57 & 2.41 \\
100 & 60 & 0.86 & 1.12 & 1.98 \\
100 & 30 & 0.39 & 0.85 & 1.23 \\
75 & 30 & 0.51 & 0.50 & 1.02 \\
50 & 15 & 0.42 & 0.67 & 1.09 \\
\hline a) & & & &
\end{tabular}

hydrates show low melting points obviously because of the amorphous morphology.

\section{Non-aqueous non-derivatizing solvents}

Important examples of non-aqueous, non-derivatizing solvents are summarized in Table 4. A more detailed description is published elsewhere. ${ }^{[9]}$

The system $N, N$-dimethylacetamide (DMA)/LiCl shows an enormous potential for the analysis of cellulose and for the preparation of a wide variety of derivatives. Its usefulness in analysis is due to the fact that the solvent is colorless and dissolution succeeds without or at least with negligible degradation even in case of high molecular weight polysaccharides, e.g., cotton linters or bacterial cellulose. Thus, it was possible to investigate the dissolved cellulose by means of ${ }^{13} \mathrm{C}$-NMR spectroscopy ${ }^{[15,16]}$, electrospray mass spectroscopy ${ }^{[17]}$, size exclusion chromatography ${ }^{[18]}$ and light scattering techniques ${ }^{[19]}$. Although it is the solvent of choice for these applications, a dissolution mechanism for cellulose in this solvent has still not been clearly postulated ${ }^{[17]}$. Different solvent-polymer structures were proposed ${ }^{[20]}$.

Other non-aqueous, non-derivatizing solvents are mixtures with the general composition: polar organic liquid/ $\mathrm{SO}_{2} /$ primary, secondary or tertiary aliphatic or secondary alicyclic amine. From the wide variety of possible mixtures dimethyl sulfoxide (DMSO)/ $\mathrm{SO}_{2} /$ diethylamine is most versatile $\mathrm{e}^{[21]}$.

In case of single component solvents, $N$-alkylpyridinium halides and $\mathrm{N}$-oxides of tertiary amines are worth mentioning. The most powerful solvents in this regard are $N$-ethylpyridinium chloride and $\mathrm{N}$-methylmorpholine- $\mathrm{N}$-oxide (NMNO). The advantage of an easy work up procedure after modification of polysaccharides in these solvents is ruled out by the fact that most of these substances are solid at room temperature, need to be applied as melts, and are highly explosive.

With the rediscovery of NMNO, which acts essentially via physical phenomena, and with the development of technical processes for the manufacture of textile cellulose fibres and filaments, an environmentally friendly alternative 
Table 4. Typical non-aqueous cellulose solvents. ${ }^{\text {a) }}$

\begin{tabular}{|c|c|c|}
\hline Number of components & Substance group & Examples \\
\hline \multirow[t]{4}{*}{ Unicomponent } & $N$-Alkylpyridinium halogenides & $N$-Ethylpyridinium chloride \\
\hline & Oxides of tertiary amines & $N$-Methylmorpholine- $N$-oxide \\
\hline & & Triethylamine- $N$-oxide \\
\hline & & $N$-Methylpiperidine- $N$-oxide \\
\hline \multirow[t]{7}{*}{ Bicomponent } & $\begin{array}{l}\text { Dimethyl sulfoxide } \\
\text { (DMSO) containing solvents }\end{array}$ & DMSO/methylamine \\
\hline & & DMSO/KSCN \\
\hline & & $\mathrm{DMSO} / \mathrm{CaCl}_{2}$ \\
\hline & & DMSO/TBAF \\
\hline & $\begin{array}{l}\text { Liquid ammonia/ } \\
\text { sodium or ammonium salts }\end{array}$ & $\begin{array}{l}\mathrm{NH}_{3} / \mathrm{NaI}\left(\mathrm{NH}_{4} \mathrm{I}\right) \\
\mathrm{NH}_{3} / \mathrm{NaSCN}\left(\mathrm{NH}_{4} \mathrm{SCN}\right)\end{array}$ \\
\hline & $\begin{array}{l}\text { Dipolar aprotic } \\
\text { solvents/LiCl }\end{array}$ & $\begin{array}{l}N, N \text {-Dimethylacetamide/LiCl } \\
N \text {-Methylpyrrolidone/LiCl }\end{array}$ \\
\hline & $\begin{array}{l}\text { Pyridine or quinoline } \\
\text { containing systems }\end{array}$ & $\begin{array}{l}\text { Pyridine/resorcinol } \\
\text { Quinoline/Ca( }(\mathrm{SCN})_{2}\end{array}$ \\
\hline \multirow[t]{4}{*}{ Tricomponent } & $\begin{array}{l}\mathrm{NH}_{3} \text { or amine/ } \\
\text { salt/polar solvent }\end{array}$ & $\mathrm{NH}_{3} / \mathrm{NaCl} / \mathrm{DMSO}$ \\
\hline & & Ethylenediamine/NaI/ \\
\hline & & $N, N$-Dimethylformamide \\
\hline & $\begin{array}{l}\mathrm{NH}_{3} \text { or amine/ } \mathrm{SO}_{2} \\
\text { or } \mathrm{SOCl} / \text { polar solvent }\end{array}$ & Diethylamine/SO $/ \mathrm{SO}_{2} \mathrm{DMO}$ \\
\hline
\end{tabular}

a) In most cases a preactivation of the cellulose is required.

of the viscose process was established ${ }^{[22-25]}$. As a result of an industrial breakthrough, fibres made from NMNO solution, Lyocell-type fibres, have begun to compete with viscose fibres. The structural differences between Lyocell and viscose fibres result from differences in the supramolecular structure - including degree of crystallinity, crystallite dimensions, and orientation of the non-crystalline chain segments - and in the cross morphology ${ }^{[26,27]}$.

NMNO is a suitable medium for a variety of alkylation reactions including hydroxyethylation, mercaptoalkylation, cyanoethylation and carboxymethylation up to DS 1.8 in an one step reaction ${ }^{[10,28]}$. Interestingly, by carboxymethylation of cellulose in NMNO/DMSO mixtures, the solvent behaves as a non-aqueous one although the reaction started with the NMNO monohydrate. Moreover, acetylation of cellulose was studied via transesterification applying vinylacetate as reagent. The product obtained possesses a rather low DS of 0.3 only and an enzyme must be applied for the conversion ${ }^{[29]}$.

A novel and powerful new solvent for cellulose consists in the mixture DMSO/tetrabutylammonium fluoride trihydrate (TBAF) ${ }^{[30]}$. The advantage of DMSO/TBAF is that cellulose with a degree of polymerization as high as 650 dissolves without any pretreatment within $15 \mathrm{~min}$. A remarkable finding was that only the fluoride is able to give clear solutions. If the halide is changed, no dissolution occurs. Highly resolved ${ }^{13} \mathrm{C}-\mathrm{NMR}$ spectra of cellulose can be obtained showing all the ring carbons of the AGU and giving no hints for a derivatization during the dissolution process (Figure 2). It should be mentioned that the solutions contain a certain amount of water because TBAF is used as commercially available trihydrate and the cellulose is air-dried only.

The solvent DMSO/TBAF is a more efficient reaction medium for transesterification reactions than NMNO. Conversions of cellulose with vinyl acetate as acylating reagent yielded cellulose acetates with DS values up to

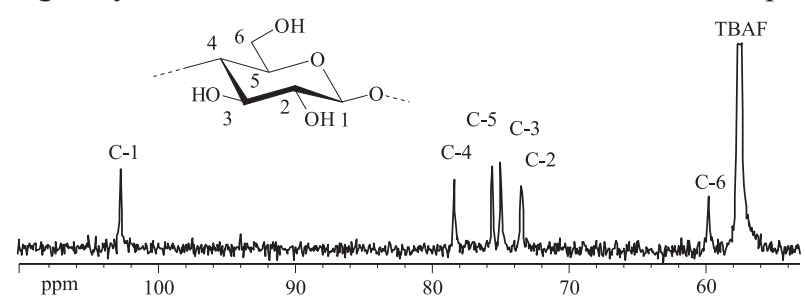

Figure 2. ${ }^{13} \mathrm{C}-\mathrm{NMR}$ spectrum of cellulose $(3 \%, \mathrm{w} / \mathrm{v})$ dissolved in dimethyl sulfoxide- $d_{6}$ /tetrabutylammonium fluoride trihydrate (TBAF). 
Table 5. Conditions and results of the acetylation of cellulose $(2.9 \%, \mathrm{w} / \mathrm{v})$ dissolved in dimethylsulfoxide/tetrabutylammonium fluoride trihydrate $(16.6 \%, \mathrm{w} / \mathrm{w})$ with vinyl acetate at $40^{\circ} \mathrm{C}$ for $70 \mathrm{~h}$.

\begin{tabular}{cccccl}
\hline $\begin{array}{c}\text { Molar } \\
\text { ratio }^{\text {a) }}\end{array}$ & $\begin{array}{c}\text { Catalyst }^{(\mathbf{b})} \\
{[\mathbf{m g}]}\end{array}$ & \multicolumn{2}{c}{ Partial DS } & DS $^{(\mathbf{c})}$ & \multicolumn{1}{c}{ Solubility } \\
\hline & & at $O-6^{(\mathrm{c})}$ & $O-2 / 3$ & & \\
\hline $1: 2.3$ & - & 0.49 & 0.55 & 1.04 & Dimethylsulfoxide \\
$1: 2.3$ & 20 & 0.52 & 0.55 & 1.07 & Insoluble \\
$1: 1.5$ & 20 & 0.39 & 0.24 & 0.63 & Insoluble \\
$1: 10.0$ & 20 & 0.98 & 1.74 & 2.72 & Dimethylsulfoxide
\end{tabular}

a) Molar ratio of vinyl acetate to anhydroglucose unit (mole/mole).

b) Mixture of $\mathrm{KH}_{2} \mathrm{PO}_{4}$ and $\mathrm{Na}_{2} \mathrm{HPO}_{4}$.

c) Degree of substitution calculated from ${ }^{1} \mathrm{H}-\mathrm{NMR}$ spectra.

$2.72^{[30,31]}$. A summary of reaction conditions and results are given in Table 5. The transesterification with vinyl acetate is more effective than acetylation with acetic anhydride, which is due to the formation of acetaldehyde during this conversion shifting the equilibrium towards the product side. On the other hand, the lower DS in case of the application of acetic anhydride is caused by the comparably fast hydrolysis of the reagent due to the water content of the solvent DMSO/TBAF. Experiments towards the dewatering of the solvent were carried out as well ${ }^{[31,32]}$.

Recently, it was found that ionic liquids especially salts containing substituted imidazolium ions are capable to dissolve cellulose over a wide range of DP values (even bacterial cellulose) with no covalent interactions ${ }^{[33]}$. Studies towards their application as reaction medium for the chemical modification of cellulose including acetylation as well as for regeneration of cellulose fibres are under progress ${ }^{[34]}$.

\section{Aprotic derivatizing solvents and soluble intermediates}

All the solvents previously discussed show physical dissolution of the polysaccharide without derivatization of any hydroxyl group. An acceptable alternative to this route is the application of so-called derivatizing solvents or the utilization of hydrolytically unstable, organo-soluble cellulose intermediates. A representative summary of such solvents and the derivatives formed in-situ is given in Figure 3.

The major disadvantage of the derivatizing solvents is the occurrence of side reactions during dissolution and the formation of undefined structures. In turn, this leads to products hardly reproducible. Nevertheless, the $N, N$ dimethylformamide (DMF) $/ \mathrm{N}_{2} \mathrm{O}_{4}$ solvent, yielding cellulose nitrite as intermediate, has found considerable interest in the synthesis of inorganic cellulose esters, e.g., cellulose sulfates despite its highly toxic nature ${ }^{[35,36]}$. Although long known as solvent, the dissolution mechanism was a long lasting controversy. Today it is a well-accepted fact that dissolution under strictly anhydrous conditions succeeds by formation of the cellulose trinitrite ${ }^{[37]}$. In this process the first step is a heterolytic cleavage of the $\mathrm{N}_{2} \mathrm{O}_{4}$ molecule, which initiates the esterification of cellulose to the nitrite. If small amounts of water are present in the solvent system, the cellulose molecule is only partially derivatized in this step with a preferred conversion of the primary hydroxyl groups. Variation of the solvent components is possible. Instead of DMF, DMSO may be applied and $\mathrm{N}_{2} \mathrm{O}_{4}$ can be substituted with $\mathrm{NOCl}$, nitrosyl sulfuric acid, nitrosyl hexachloroantimonate or nitrosyl tetrafluoroborate yielding solutions within the same time.

A rather interesting derivatizing solvent is the mixture $\mathrm{DMSO} /$ paraformaldehyde. The major advantage of this system is that it dissolves cellulose rapidly and almost without degradation even in case of high molecular weight polymers. Cellulose is here dissolved by formation of the hemiacetal, i.e., so-called methylol cellulose is obtained (Figure 3). ${ }^{13} \mathrm{C}$-NMR spectroscopy revealed that the acetalization occurs preferentially at the 6 position of the $\mathrm{AGU}^{[38,39]}$. The methylol functions can be easily removed by a treatment with water. Noteworthy is the fact that during the dissolution a growth of oligooxy methyleneoxide chains may occur.

The intermediates formed during the dissolution of the polysaccharide could be isolated prior to the conversion into a final cellulose derivative. There is an increasing reproducibility due to the fact that structure analysis of the intermediates is possible, on one hand. On the other, these intermediates can be dissolved in a wide variety of common organic solvents, which decreases the tendency towards side reactions drastically (especially degradation). Therefore, reactive intermediates can be the starting material for a variety of highly engineered derivatives. Besides the investigation of trialkylsilyl derivatives in this regard and subsequent functionalization of the rather reactive cellulose xanthogenate, which was only of limited interest in the context of reactive intermediates compared with its wide utilization for cellulose

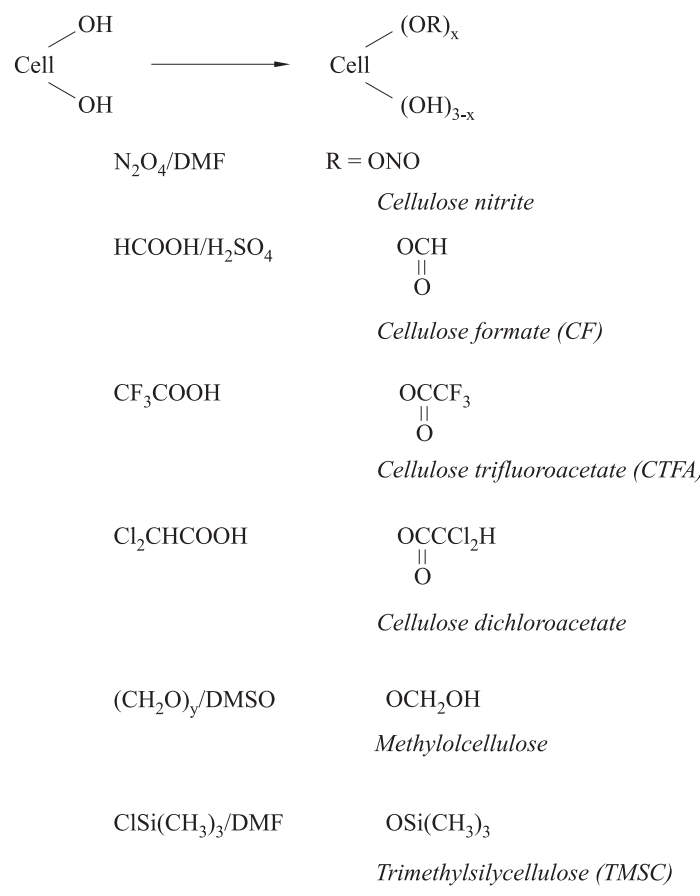

Figure 3. Representative examples of derivatizing solvents of cellulose and intermediates formed. 
regeneration, cellulose formate (CF) and halogenoacetic acid esters of cellulose are the most studied intermediates within this new strategy of functionalization.

The interaction of cellulose with formic acid was applied to determine the degree of disorder of the cellulose structure and the chemical accessibility of the hydroxyl groups. Moreover, solutions of cellulose in formic acid and CF were studied in terms of their hydrolytic and thermal stability and their potential for cellulose fibre preparation by regeneration ${ }^{[40]}$.

$\mathrm{CF}$ can be isolated from mixtures of cellulose, formic acid, phosphoric acid and water ${ }^{[41]}$. They are soluble in DMF and DS values of up to 1.2 are reached. The acylation takes place in the order $C-6>C-2>C-3$ as revealed by ${ }^{13} \mathrm{C}-\mathrm{NMR}$ spectroscopy. If sulfuric acid is applied as catalyst, the reaction is completed within $15 \mathrm{~min}$. The CF prepared has a DP of about 200 (DP of the starting cellulose was 600 ). In case of the application of partially hydrolyzed $\mathrm{POCl}_{3}$ as swelling and dehydrating agent it is possible to increase the DS of up to 2.2 yielding formate samples soluble in DMSO, DMF and pyridine with DP values of 280 (starting from spruce sulfite pulp, $\mathrm{DP}=680$ ) within $4 \mathrm{~h}$ reaction time ${ }^{[42]}$.

Solutions of cellulose as well as of chitosan in trifluoroacetic acid (TFA) were extensively studied by means of NMR spectroscopy showing that the primary $\mathrm{OH}$ groups are almost completely functionalized ${ }^{[43,44]}$. The interaction of cellulose and TFA was investigated in terms of its kinetics ${ }^{[45]}$. The dissolution of cellulose in mixtures of TFA with different organic liquids strongly depends on the electron acceptor behaviour of the liquid. Furthermore, during dissolution of cellulose in mixtures containing TFA/ $\mathrm{CH}_{2} \mathrm{Cl}_{2}$ trifluoroacetylation occurs only to a limited extent and the polysaccharide is rather slowly degraded ${ }^{[46]}$. Interestingly, the solutions show the formation of mesophases starting from cellulose concentrations as low as $4 \%(\mathrm{w} / \mathrm{w})$, which can be used to regenerate strong fibres.

Pure cellulose trifluoroacetates (CTFA) soluble in DMSO, pyridine, and DMF can be easily prepared by treating cellulose with mixtures of TFA and its anhydride. These intermediates had DS values of 1.5 and were completely substituted at the C-6 position as can be concluded both from ${ }^{13} \mathrm{C}$-NMR spectroscopy and from HPLC after methylation, saponification and complete depolymerization. Thereby the inverse pattern of functionalization of the methylether functions is determined. If the trifluoroacetylation is carried out in the presence of chlorinated hydrocarbons as co-solvents (e.g., chloroform), the DS can be increased of up to 2.2 yielding products that are soluble in tetrahydrofuran.

The dissolved cellulose as well as all cellulose intermediates described can be applied in subsequent functionalization reactions in homogeneous phase. Thus, a wide variety of organic esters, inorganic esters, carbamates, and ethers with a specific distribution of functional groups were prepared.

\section{Conclusions}

The results discussed show that solvents play and continue to play an important route in the field of cellulose research and development. There will be an improvement in the area of shaping and analysis applying new solvents or at least by applying modified solvent mixtures including activation prior to dissolution. The homogeneous phase chemistry has contributed to the development of tailored cellulose derivatives with a variety of promising properties. It seems to be possible that homogeneous conversions will get commercial importance at least for start up companies which will prepare highly engineered products. In this context further research is necessary especially with regard to efficient dissolution procedures, polymer concentration, simple work up procedures, recycling, etc.

\section{Acknowledgments}

The financial support of the "German Science Foundation" (DFG), the "Funds of the Chemical Industry of Germany" (FCI), and of the companies sponsoring the Center of Excellence for Polysaccharide Research Jena-Rudolstadt supporting the own research in the field is gratefully acknowledged.

\section{References}

1. Cross, C. F.; Bevan, B. T. \& Beadle, C. - Ber. Dtsch. Chem. Ges. 1893, 26, 1090 and 2520.

2. Jayme, G. - Papier (Darmstadt) 32, 145, (1978).

3. Krässig, H. A.; Steadman, R. G.; Schliefer, K. \& Albrecht, W. - Cellulose, in : "Ullmann's Encyclopedia of Industrial Chemistry", eds. W. Gerhartz et al., VCH, Weinheim, $5^{\text {th }}$ Ed., Vol. A5, VCH, Weinheim, 413ff (1986).

4. Zhang, L. ; Yang, G. \& Xiao, L. - J. Membr. Sci. 103, 65 (1995).

5. EP 807460 A1 19971119, Akzo Nobel NV, invs. Diamantoglou, M., M Nywlt, W. Hoelz; Chem. Abstr. 128, 66541 (1997).

6. Hoenich, N. A.; Woffindin, C.; Stamp, S.; Roberts, S. J. \& Turnbull, J. - Biomaterials 18, 1299 and references cited therein (1997).

7. Isogai, A. \& Atalla, R. H. - Cellulose 5, 309 (1998).

8. Burger, J.; Kettenbach, G. \& Klüfers, P. - Macromol. Symp. 99, 113 (1995).

9. Heinze, Th. \& Liebert, T. - Cellul. Chem. Technol. 32, 3 (1998).

10. Heinze, Th.; Liebert, T.; Klüfers, P. \& Meister, F. - Cellulose 6, 153 (1999).

11. Heinze, Th. \& Pfeiffer, K. - Angew. Makromol. Chem. 266, 37 (1999).

12. Fischer, S.; Voigt, W.; Fischer, K. - Cellulose 6, 213 (1999). 
13. Fischer, S.; Leipner, H.; Brendler, E.; Voigt, W.; Fischer, K. in "Polysaccharide Applications, Cosmetics and Pharmaceuticals", eds. M.A. El-Nokaly, H. A. Soini, ACS Symposium Series 737, Washington DC, 143ff (1999).

14. Fischer, S. - Habilitation Thesis TU Bergakademie Freiberg, Germany (2003).

15. Nehls, I.; Wagenknecht, W.; Philipp, B. - Cellul. Chem. Technol. 29, 243 (1995).

16. El-Kafrawy, A. - J. Appl. Polym. Sci. 27, 2435 (1982).

17. Striegel, A. M. - Carbohydr. Polym. 34, 267 (1997).

18. Silva, A. A.; Laver, M. L. - TAPPI, 80, 173 (1997).

19. Sjöholm, E.; Gustafsson, K.; Eriksson, B.; Brown, W.; Colmsjö, A. - Carbohydr. Polym. 41, 153 (2000).

20. El Seoud, O. A.; Marson, G.; Ciacco, G. T.; Frollini, E. Macromol. Chem. Phys. 201, 882 (2000).

21. Isogai, A.; Ishizu, A.; Nakano, J. - J. Appl. Polym. Sci. 33, 1283 (1987).

22. DE 713486 19411016, Gesellschaft für Chemische Industrie, Basel, invs. Ch. Gränacher, R. Sallmann, Chem. Abstr. 38, 10955 (1941).

23. GB 1144048 19690305, Eastman Kodak Co., inv. D. L. Johnson; Chem. Abstr. 70, 106537 (1996).

24. GB 1144759 19690312, Eastman Kodak Co., inv. D. L. Johnson; Chem. Abstr. 70, 107081 (1996).

25. Taeger, E.; Michels, Ch.; Nechwatal, A. - Papier (Darmstadt) 45, 784 (1991).

26. Weigel, P.; Fink, H.-P.; Walenta, E.; Ganster, J.; Remde, H. - Cellul. Chem. Technol. 31, 321 (1997).

27. Fink, H.-P.; Weigel, P.; Purz, H.-J.; Ganster, J. - Prog. Polym. Sci. 26, 1473 (2001).

28. Kötz, J.; Philipp, B.; Nehls, I.; Heinze, Th.; Klemm, D. Acta Polym. 41, 333 (1990).

29. DE 19951734A1, Wolff Cellulosics GmbH \& Co KG, invs.: E.-A. Klohr, W. Koch, D. Klemm, R. Dicke; Chem. Abstr. 133, 224521 (2000).
30. Heinze, Th.; Dicke, R.; Koschella, A.; Kull, A. H.; Klohr, E.A.; Koch, W. - Macromol. Chem. Phys. 201, 627 (2000).

31. Ciacco, G. T.; Liebert, T. F.; Frollini, E.; Heinze, T. J. Cellulose 10, 125 (2003).

32. Ass, B. A. P.; Frollini, E.; Heinze, Th. - Macromol. Biosci., 4, 1008 (2004).

33. Swatloski, R. P.; Spear, S. K.; Holbrey, J. D.; Rogers, R. D. - J. Am. Chem. Soc. 124, 4974 (2002).

34. K. Schwikal, Diploma Thesis 2003, University of Jena, Germany.

35. Wagenknecht, W.; Nehls, I.; Philipp, B. - Carbohydr. Res. 240, 245 (1993).

36. Klemm, D.; Heinze, Th.; Philipp, B.; Wagenknecht, W. Acta Polym. 48, 277 and references cited therein (1997).

37. Wagenknecht, W.; Nehls, I.; Philipp, B. - Carbohydr. Res. 237, 211 (1992).

38. Johnson, D. C.; Nicholson, M. D.; Haigh, F. C. - Appl. Polym. Symp. 28, 931 (1976).

39. Baker, T. J.; Schroeder, L. R.; Johnson, D. C. - Cellul. Chem. Technol. 15, 311 (1981).

40. Fujimoto, T.; Takahashi, S.; Tsuji, M.; Miyamoto, T.; Inagaki, H. - J. Polym. Sci., Part C: Polym. Lett. 24, 495 (1986).

41. Schnabelrauch, M.; Vogt, S.; Klemm, D.; Nehls, I.; Philipp, B. - Angew. Makromol. Chem. 198, 155 (1992).

42. Liebert, T.; Klemm, D.; Heinze, Th. - J. M. S. Pure Appl. Chem. A33, 613 (1996).

43. Hasegawa, M.; Isogai, A.; Onabe, F.; Usuda, M. - J. Appl. Polym. Sci. 45, 1857 (1992).

44. Nehls, I.; Wagenknecht, W.; Philipp, B.; Stscherbina, D. Prog. Polym. Sci. 19, 29 (1994).

45. Cemeris, M.; Musko, N. P.; Cemeris, N. - Khim. Drev. 2 , 29 (1986).

46. Hawkinson, D. E.; Kohout, E.; Fornes, R. E.; Gilbert, R. D. - J. Polym. Sci., Part B: Polym. Phys. 29, 1599 (1991). 